\title{
Some effects of methylphenidate on self-punitive running in rats
}

\author{
BRIAN M. KRUGER, PAUL M. LAVIN, PATRICK E. CAMPBELL, \\ and HARRY N. DAVIS \\ Wright State University, Dayton, Ohio 45435
}

\begin{abstract}
Self-punitive behavior was demonstrated in prepunishment speeds during extinction following shock-escape training in a straight runway under no-dose, low-dose (1-mg/kg), and high-dose $(10-\mathrm{mg} / \mathrm{kg})$ methylphenidate conditions. Increased dosage enhanced punished running (shock in the last half of the runway) and nonpunished running. Self-punitive behavior, defined as the difference between punishment conditions with faster running or increased persistence under punishment conditions, was not significantly affected by the drug variable. The results were interpreted as compatible with conditioned fear interpretations of self-punitive behavior but nonsupportive of cognitive interpretations.
\end{abstract}

Numerous experiments have reported greater resistance to extinction and/or faster extinction running speeds for rats receiving self-administered shock between the startbox and the goalbox during extinction than for rats receiving no shock during extinction following escape or avoidance conditioning (see Brown, 1969; Melvin, 1971, for reviews). Mowrer's (1947) explanation of continued self-punitive running stressed the concept of a conditioned fear response. According to this view, fear is conditioned to startbox stimuli during acquisition and motivates running during extinction. Fear is maintained in extinction by the onset of shock in the alley, and reduction in fear as the rat enters the goalbox continues to strengthen the running response, as during training. Supplementary to this early view, Brown (1969) has suggested some other factors that may contribute to self-punitive running, such as residual emotionality from preceding trials and maintenance of running by offset of shock as well as offset of feareliciting stimuli upon entering the goalbox.

While the Mowrer-Brown interpretation has been the most frequently cited explanation of self-punitive running, it has not gone unchallenged. Renner and Tinsley (1976) have suggested that rats run selfpunitively as a result of confusion. According to this view, punished rats run longer than nonpunished rats because the presence of shock in the runway confuses them with respect to the presence or absence of shock in the startbox. Renner and Tinsley suggest that any variable that affects the time spent in the startbox should affect self-punitive running and self-punitive behavior (the difference between punished and nonpunished groups, with stronger performance for the punished group). That is, the less time a punished rat spends in the start-

Requests for reprints should be sent to Brian M. Kruger, Department of Psychology, Wright State University, Dayton, Ohio 45435. box, the longer it should be before the rat discovers that contingencies for shock have changed and quits running. According to this position, if enhanced fear to startbox cues results in faster starting speeds, resistance to extinction should be enhanced. Thus, while they attribute the cause of self-punitive behavior to confusion rather than to conditioning of fear, Renner and Tinsley do not take issue with the view that punished and nonpunished running as well as self-punitive behavior may vary with factors that affect the degree of conditioning of fear to startbox stimuli.

Methylphenidate was manipulated in the present experiment in an attempt to test contrasting predictions from the Mowrer-Brown position and the discrimination hypothesis as advanced by Renner and Tinsley (1976). Methylphenidate is a piperidine derivative that produces central nervous system stimulation similar to that produced by amphetamine (Goodman \& Gilman, 1970). Evidence from both humans and animals (rats) supports the view that methylphenidate increases activity but does not affect emotionality (Baum, 1973; Blacow, 1972; Dyne \& Hughes, 1970; Gauron \& Rowley, 1976; Hughes \& Grieg, 1976). If methylphenidate increases activity but has no effect on emotionality or fear, then a fear conditioning interpretation would seem to predict that self-punitive running and nonpunished running should be enhanced equivalently by methylphenidate and that self-punitive behavior (the difference between punished and nonpunished performances) should not be affected. In contrast, it seems to follow from Renner and Tinsley's (1976) view that reducing starting time by increasing activity with methylphenidate should increase confusion for the punished rats and thereby increase self-punitive behavior.

In the present experiment methylphenidate was injected after acquisition of the escape response to avoid confounding of terminal acquisition performances with drug dosage. A waiting period intervened between injec- 
tion immediately following acquisition and the start of extinction to prevent any running in the absence of shock in all or part of the runway prior to the drug's taking effect. A second purpose of the delay was to reduce running speeds for no-dose groups so that there would be "room" for improvement in running speed performance and for enhancement of self-punitive behavior by drug administration. Melvin, Martin, and Parsons (1965) reported that an 18-min delay between shockescape training and extinction greatly reduced resistance to extinction.

Bindra and Baran (1959) have shown that medium doses of methylphenidate $(.5 .7 \mathrm{mg} / \mathrm{kg})$ increase general activity, with peak effects occurring 30-60 min after injection. (No measures were taken from 10 to $30 \mathrm{~min}$ after injection.) Thus, in the present study, in which the testing period was limited to approximately $20 \mathrm{~min}$, beginning $20 \mathrm{~min}$ after injection, the effect of methylphenidate upon self-punitive behavior should have been assessed during periods of maximal or near maximal drug effects.

\section{METHOD}

\section{Subjects}

A total of 73 naive male hooded rats, purchased from Maxfield Animal Supply, Cincinnati, Ohio, and ranging in weight from 169 to $392 \mathrm{~g}$, were used. Of the original 69 rats randomly assigned to conditions, 4 were replaced for procedural reasons given below. All rats were individually caged and maintained with free access to Purina Lab Chow and water.

\section{Apparatus}

The apparatus consisted of a two-compartment (upper and lower) startbox, straight alley, and goalbox. The lower startbox and alley had grid floors (2.4-mm-diam stainless steel rods spaced $1.3 \mathrm{~cm}$ apart). The walls and subfloors $(3.2 \mathrm{~cm}$ below the grid) of the lower startbox and alley were translucent white plastic (Plexiglas), as were the lids of the alley and upper startbox. The walls, floor, and lid of the goalbox were black. The startbox was divided into an upper gray compartment $(20.3 \mathrm{~cm}$ long $\times 8.9 \mathrm{~cm}$ wide $\times 17.8 \mathrm{~cm}$ high, inside) and a lower compartment $(30.5 \mathrm{~cm}$ long $\times 10.2 \mathrm{~cm}$ wide $\times 22.9 \mathrm{~cm}$ high, inside) by a gray metal trapdoor-like floor. This floor was hinged $22.9 \mathrm{~cm}$ above the grid. When released, the floor swung down and became the back wall of the lower starting area. Activation of a series of incandescent lights below the alley and startbox produced a uniform illumination level of approximately $6.5 \mathrm{~lx}$.

The runway $(122 \mathrm{~cm}$ long $\times 10.2 \mathrm{~cm}$ wide $\times 20.3 \mathrm{~cm}$ high, inside) was physically uniform throughout. Sets of three photocells $(3.2,6.4$, and $8.9 \mathrm{~cm}$ above the grid) and associated infrared sources were positioned at the beginning, middle, and the end of the alley. By means of associated electronic equipment (Kruger, 1974), measurements to the nearest $.01 \mathrm{sec}$ were made of starting time (the interval from the release of the trapdoor until the interruption of any one of the three horizontal beams falling on the first set of photocells) and the time elapsed in traversing each of the two $61-\mathrm{cm}$ alley segments.

A Hunter Model 393 guillotine door $(7.6 \mathrm{~cm}$ wide x $12.7 \mathrm{~cm}$ high), modified for automatic electrical control, separated the alley from the goalbox $(20.3 \mathrm{~cm}$ high $\times 10.2 \mathrm{~cm}$ wide for $5.1 \mathrm{~cm}$ adjacent to the door and $20.3 \mathrm{~cm}$ wide for the remaining $40.6 \mathrm{~cm})$. Single photocells, employed in sensing the rat's location and located $3.2 \mathrm{~cm}$ above the floor, were spaced $5.1 \mathrm{~cm}$ apart in the goalbox beginning $2.5 \mathrm{~cm}$ inside the doorway, plus one at $1.3 \mathrm{~cm}$ inside the doorway. The door closed in less than $.6 \mathrm{sec}$ when the rat entered the goalbox far enough to first obstruct and then reinstate the first infrared beam inside the goalbox. The door stopped and locked $1.3 \mathrm{~cm}$ above the grid to prevent pinching the rat's tail if it was in the doorway. The alley and startbox lights were turned off when the door closed, to prevent light from entering the goalbox through the gap below the door.

The startbox grid and the two halves of the alley grid could be separately activated for electric footshock administration. Scrambled shock was delivered by I-O-Tek Model 101 shock scramblers. The momentary potentials were ground for one output and $+100 \mathrm{~V}$ dc via $47 \mathrm{~K}$ series resistors for the other eight outputs. The rear wall of the lower startbox (the metal trapdoor) was connected to one output of the startbox shock scrambler to reduce the probability of a rat's escaping shock by leaning against this wall with its forepaws.

The rats were run in a carpeted sound-reduction room. Ceiling-mounted speakers provided background white noise and raised the noise level from approximately $54 \mathrm{~dB}$ to $72 \mathrm{~dB}$ within the alley (General Radio Company Type 1565-A sound level meter, $\mathrm{C}$ scale). The room was dark except for low level ambient light from the illumination sources employed for the apparatus.

\section{Procedure}

Each rat was placed in the goalbox and allowed to explore the entire apparatus for $10 \mathrm{~min}$ prior to running. Immediately following this habituation period, the first of 30 acquisition trials was begun, with shock present throughout the grid areas. On each trial the rat was placed in the upper startbox and dropped after a $10-\mathrm{sec}$ delay. Unseen by the rats through the opaque trapdoor, the lights for the lower startbox and alley were turned on $2 \mathrm{sec}$ before the drop on all trials in all phases. These lights were terminated when the door to the goalbox began to close. The rat remained in the goalbox for $40 \mathrm{sec}$ after door closure. The end of this interval was signaled to the experimenter by a small lamp. Approximately $10 \mathrm{sec}$ elapsed in removing the rat from the goalbox, placing it in the upper startbox, and pressing a switch to begin the $10-\mathrm{sec}$ delay. This interval completed the $60-\mathrm{sec}$ interval from goalbox door closure to drop.

All rats received an intraperitoneal injection $1 \mathrm{~min}$ after the last acquisition trial and were placed in a standard wire-floored metal cage in the apparatus room for a 20 -min waiting period. One-third of the original 69 rats received a high-dose drug injection $(10 \mathrm{mg} / \mathrm{kg}$ of body weight), one-third received a lowdose injection $(1 \mathrm{mg} / \mathrm{kg})$, and one-third received a no-dose treatment of injection of the same volume of the sterile water vehicle ( $1 \mathrm{cc} / \mathrm{kg}$ of body weight).

Three rats within each drug dosage condition were given 20 additional escape trials after the waiting period with shock throughout the alley. These rats were designated the continued acquisition rats.

For half of the remaining rats within each drug dosage condition (10 rats), there was no shock in the startbox or alley during extinction. These nonpunished groups of rats were identified by drug dosage ( $0-\mathrm{NP}, 1-\mathrm{NP}$, and 10-NP for no-dose, low-dose, and high-dose groups, respectively). For the remaining 10 rats within each drug dosage condition, there was shock in the last $61-\mathrm{cm}$ section of the alley but not in the first alley segment or in the lower startbox. These punished groups of rats were also identified by drug dosage (0-P, 1-P, and 10-P).

Essentially the same procedures were used for extinction trials as for acquisition trials. The criterion for extinction was the failure to break one of the beams at the goalbox end of the alley within $60 \mathrm{sec}$ from the release of the trapfloor. Arbitrary times of $60 \mathrm{sec}$ were entered for all measures not obtained on the criterial trials and for all trials after the criterion was met. If a rat broke the beam at the end of the alley within the $60-\mathrm{sec}$ period but failed to enter the goalbox far enough to activate the door-closure circuit within $60 \mathrm{sec}$ after the drop, the rat was manually removed and placed in the goalbox to complete the $40-\mathrm{sec}$ waiting period. A maximum of 20 extinction trials was administered. 
If on the first trial of extinction a rat failed to receive the self-administered treatment of shock or no shock in the second segment by failure to enter the second segment of the alley, the rat was dropped from the study and a replacement was run. Failure to enter the second segment did not appear to be affected by drug dosage; four rats were replaced, one no-dose and three low-dose rats.

\section{RESULTS}

The mean starting, first-segment, and second-segment speeds for the last block of five acquisition trials and the four blocks of five trials during extinction or continued acquisition are shown in Figure 1. Separate analyses were conducted for continued acquisition groups and for the six extinction groups.

Since analyses for the continued acquisition groups found no significant differences among groups during acquisition or during continued acquisition for any of the three speed measures, drug conditions were disregarded, and the mean speeds for all nine continued acquisition rats were computed and are plotted in Figure 1. The means for the four blocks of continued acquisition are plotted with the extinction means for the other groups. The fast speeds for the continued acquisition indicate that the drug did not interfere with physical ability to run.

The analyses of acquisition data for the groups receiving extinction trials found no significant differences among groups for any of the three speed measures. The results of analyses of extinction data were virtually identical for all three measures. The $\mathrm{F}$ test results given below, when not individually identified, are in each instance given sequentially for starting, first-segment, and second-segment tests, respectively (.05 level of significance for all tests).

All main effects were significant for all three speed measures [trials: $\mathrm{Fs}(3,162)=5.24,17.29$, and 4.58; drug dosage: $\operatorname{Fs}(2,54)=5.45,5.30$, and 4.05; and extinction punishment conditions: $\mathrm{Fs}(1,54)=4.16$, 9.10 , and 32.22]. Significant interactions between drug dosage and trials for all measures $[\operatorname{Fs}(6,162)=$ $4.08,9.26$, and 6.09] supported the indication from inspection of Figure 1 that the effects of the drug variable developed or increased with trials.

The presence of significant extinction punishment condition main effects supported the indication from inspection of Figure 1 that overall self-punitive behavior effects were present for all measures. The indication from inspection of Figure 1 that these effects developed or increased over trials was supported by significant interactions between extinction punishment conditions and trials for all measures $[\mathrm{Fs}(3,162)=11.16,14.21$, and 23.64]. Follow-up tests within drug levels showed that the effects developed or increased over trials for no-dose and low-dose conditions for all measures $[F s(3,162)=6.37,7.30$, and 9.78 , for no dose; $\operatorname{Fs}(3,162)=4.66,7.35$, and 13.34 for low dose]. For the high-dose level the interaction was significant only for second-segment speeds $[F(3,162)=3.21]$. Addi-
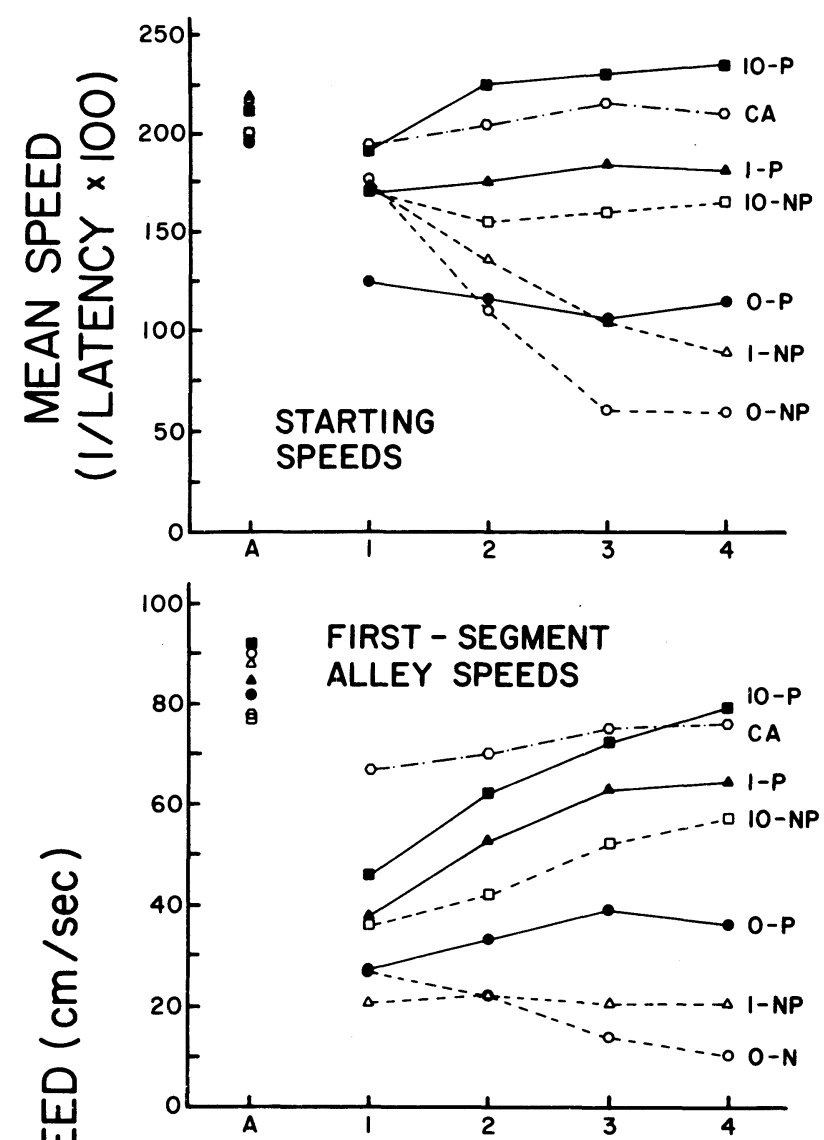

崩

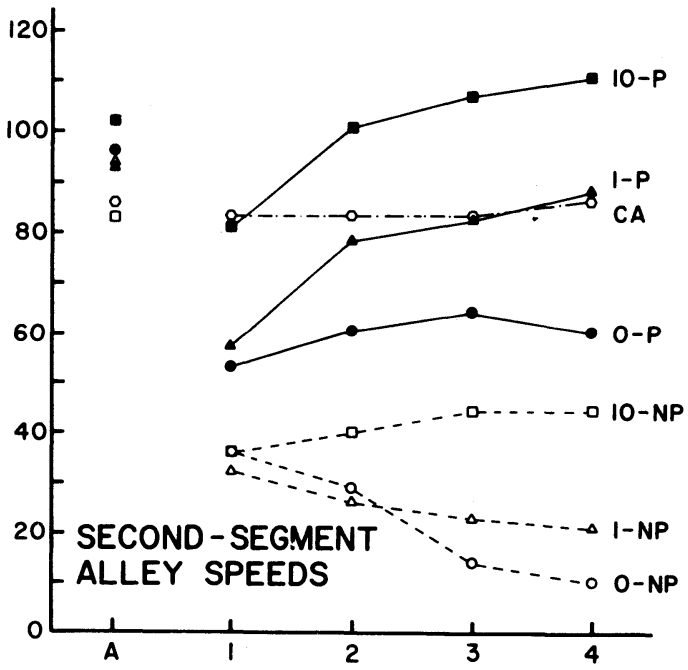

\section{BLOCKS OF FIVE TRIALS}

Figure 1. Mean starting, first-segment, and second-segment speeds for the last block of acquisition and four blocks of extinction (1-P, 10-P, 1-NP, and 10-NP) or continued acquisition (CA).

tional follow-up tests within drug levels for the last two blocks supported the indication from inspection of Figure 1 that self-punitive behavior was demonstrated at all dose levels. For the no-dose level, selfpunitive behavior was present for first-segment and second-segment speeds $[\mathrm{Fs}(1,54)=7.09$ and 20.47 , 
respectively], but the difference between punished and nonpunished starting speeds only approached significance $[F(1,54)=3.47, p<.10]$. Self-punitive behavior was present for the low-dose level for all measures $[\operatorname{Fs}(1,54)=9.66,20.37$, and 33.72] and for the highdose level for all measures $[\operatorname{Fs}(1,54)=6.40,4.85$, and 33.88].

The overall analysis found no significant interactions for any measures between drug dosage and extinction punishment conditions (all Fs $<1.0$ ) and no significant three-factor interactions involving drug dosage, extinction punishment conditions, and trials (all Fs $<1.35$ ). These results support a conclusion that the magnitude of the self-punitive effect did not differ significantly with drug dosage. Despite these results, additional planned follow-up assessments of possible interactions between drug levels and punishment conditions were conducted for the last two blocks of extinction, with the same results (all Fs $<1.0$ ). Thus, there was no evidence that the magnitude of the self-punitive effect differed with drug dosage.

The numbers of rats completing all 20 extinction trials under punishment conditions were 6,8 , and 10 for no-dose, low-dose, and high-dose conditions, respectively; under nonpunishment conditions, the numbers were 3,4 , and 7 , respectively. The differences of three, four, and three in the numbers of punished and nonpunished rats running under no-dose, low-dose, and high-dose conditions, respectively, do not provide evidence that the magnitude of the self-punitive effect differed with drug dosage.

\section{DISCUSSION}

Increasing the dosage of methylphenidate increased the number of rats running all 20 extinction trials and increased starting and running speeds under both punished and nonpunished conditions, but it had no effect on the magnitude of self-punitive behavior, defined as the difference between punishment conditions with faster running or increased persistence under punishment conditions. These results seem to be explainable on the basis of drug-produced increases in activity and are compatible with the view that methylphenidate does not affect emotionality or fear. The results failed to provide any evidence that selfpunitive behavior can be artifactually affected by increasing activity and failed to support expectations derived from Renner and Tinsley's (1976) confusion hypothesis.

Despite the position taken in the introduction that methylphenidate does not increase emotionality or fear, another explanation of the present results to consider is that methylphenidate may have increased emotionality or fear and the increased speeds for both punished and nonpunished drugged rats were due at least in part to drug-produced increases in emotionality or fear. Martin, Deemer, McArdle, Stokely, and Steiner (1971) reported that chlorpromazine reduced the magnitude of selfpunitive behavior. If it can be assumed that chlorpromazine reduced emotionality or fear, then their results suggest that reducing emotionality or fear will reduce self-punitive behavior. The obvious implication is that increased emotionality or fear should increase self-punitive behavior. Since methylphenidate did not increase self-punitive behavior, the present results suggest that methylphenidate does not enhance emotionality or fear.

\section{REFERENCES}

BAUM, M. Extinction of avoidance in rats: The effects of chlorpromazine and methylphenidate administered in conjunction with flooding response (prevention). Behaviour Research and Therapy, 1973, 11, 165-169.

Bindra, D., \& Baran, D. Effects of methylphenidylacetate and chlorpromazine on certain components of general activity. Journal of the Experimental Analysis of Behavior, 1959, 2, 343-350.

Blacow, N. W. (Ed.). Martindale: The extra pharmacopoeia (26th ed.). London: Pharmaceutical Press, 1972.

Brown, J. S. Factors affecting self-punitive locomotor behavior. In B. A. Campbell \& R. M. Church (Eds.), Punishment and aversive behavior. New York: Appleton-Century-Crofts, 1969.

Dyne, L. J., \& Hughes, R. N. Effects of methylphenidate on activity and reactions to novelty in rats. Psychonomic Science, 1970, 19, 267-268.

Gauron, E. F., \& Rowley, V. N. Use of a cross-over design in testing short-term methylphenidate effects on avoidance conditioning. Psychological Reports, 1976, 39, 1183-1187.

Goodman, L. S., \& Gilman, A. (Eds.). The pharmacological basis of therapeutics (4th ed.). London: Macmillan, 1970.

Hughes, R. N., \& Grieg, A. M. Effects of caffeine, methamphetamine and methylphenidate on reactions to novelty and activity in rats. Neuropharmacology, 1976, 15, 673-676.

KRUGER, B. M. A computer-compatible technique for the recording of successive events as in a one-way alley. Behavior Research Methods \& Instrumentation, 1974, 6, 72.

Martin, R. C., Deemer, B. L., McArdee, N., Stokely, S., $\&$ Steiner, S. The effects of chlorpromazine on self-punitive behavior. Psychonomic Science, 1971, 23, 339-340.

Melvin, K. B. Vicious circle behavior. In H. D. Kimmel (Ed.), Experimental psychopathology: Recent research and theory. New York: Academic Press, 1971.

Melvin, K. B., Martin, R. C., \& Parsons, G. Delayed extinction of escape responses: A parametric study. Psychonomic Science, 1965, 2, 247-248.

Mowrer, O. H. On the dual nature of learning-A reinterpretation of "conditioning" and "problem solving." Harvard Educational Review, 1947, 17, 102-148.

Renner, K. E., \& Tinsley, J. B. Self-punitive behavior. In G. H. Bower (Ed.), The psychology of learning and motivation (Vol. 10). New York: Academic Press, 1976.

(Received for publication January 7, 1980.) 